\title{
Chicken Meat Rich in Selenium and Omega-3 Fatty Acids
}

\author{
Anna Haug*,1, Olav A. Christophersen ${ }^{2}$ and Trine $\operatorname{Sogn}^{3}$
}

${ }^{I}$ Department of Animal and Aquacultural Sciences, Norwegian University of Life Sciences, 1432 Ass, Norway; ${ }^{2}$ Ragnhild Schibbyesvei 26, 0968 Oslo; ${ }^{3}$ Department of Soil and Plant Sciences, Norwegian University of Life Sciences, 1432 As, Norway

\begin{abstract}
The concentration of selenium (Se) in food is in many countries too low and the ratio between omega-6 and omega-3 fatty acids too high implying more non-communicable diseases, e.g. cancer, cardiac disease, impaired immune defense, pain, enhanced non-infectious inflammatory response. Meat from animals supplemented with Se and omega-3 fatty acids makes a good source of these nutrients in human nutrition. The worldwide demand for several nutrients is increasing, and food with optimal composition is required. The objective of the present study was to produce chicken meat especially high in Se and with a favorable ratio between omega-6 and omega-3 fatty acids. Sixty newly hatched chickens were fed wheat-based diets containing $40 \mathrm{~g}$ rapeseed oil $/ \mathrm{kg}, 10 \mathrm{~g}$ linseed oil $/ \mathrm{kg}$ and varying amounts of selenium enriched yeast for three weeks, resulting in meat with a favorable ratio between omega- 6 and omega-3 fatty acids and with selenium concentration ranging from 0.2 to $0.6 \mathrm{mg} / \mathrm{kg}$. This meat would be expected to give health benefits both in prophylactic and therapeutic contexts. It represents a better strategy for increasing the intake of Se and very long chain omega-3 fatty acids at a population basis rather than relying on Se supplements or only on fish resources that are already overexploited and can not cover EPA and DHA requirements (for ensuring optimal health) for more than a fraction of the world's total population. The meat from the highest Se supplementation treatment groups might be useful for some groups of patients (e.g. with ischemic pain) who might benefit from especially high Se intake.
\end{abstract}

Keywords: Chicken, meat, selenium, fatty acids, health.

\section{BACKGROUND}

Sea fish products have high natural concentrations of long-chain omega-3 fatty acids (especially in fat fish) and selenium. Meat is usually regarded as less beneficial than fish for protection against cardiovascular diseases and cancer. Chicken meat, however, is commonly regarded both by health professionals and the general public as healthful type of meat; it is well-liked, and the consumption is increasing [1]. Chicken meat is lean, protein-rich and good source of important micronutrients, such as zinc and vitamin $\mathrm{B}_{12}$. The concentration of selenium (Se) in chicken breast meat in Scandinavia is, however, only about $0.01 \mathrm{mg} / 100 \mathrm{~g}[2,3]$, while fish fillet contains about 3 to 4 times as much. [2,4]. In chicken thigh meat the total amount of the very long chain omega-3 fatty acids eicosapentaenoic acid (EPA), docosapentaenoic acid (DPA) and docosahexaenoic acid (DHA), as given by the Danish food composition table, is about 0.06 $\mathrm{g} / 100 \mathrm{~g}$, while in cod it is $0.26 \mathrm{~g} / 100 \mathrm{~g}$ and in fatty fish such as salmon it is about $2.8 \mathrm{~g} / 100 \mathrm{~g}$ [2]. These figures show that nowadays fish fillet is not only a better source of Se, but also a much better source for omega-3 fatty acids than chicken meat.

The Se concentration and fatty acid composition in chicken meat depend largely on the composition of the diet

*Address correspondence to this author at the Department of Animal and Aquacultural Sciences, Norwegian University of Life Sciences, P.O.Box 5003, 1432 Ås, Norway; Tel: +47 649651 72; Fax: +47 649651 01;

E-mail: anna.haug@umb.no fed to the birds. It has earlier been shown that feeding poultry with omega-3 fatty acids from rapeseed oil and linseed oil increases the concentrations of alpha-linolenic acid (ALA), EPA, DPA and DHA in broiler thigh muscle, and improves the ratio between omega- 6 and omega-3 fatty acids $[5,6]$, and also that dietary supplements of Se-enriched yeast increase the Se concentration of the meat [7]. Chicken feed is cereal-based (wheat, barley or corn), and the added dietary fat is mostly rendered fat and vegetable oils, having a high ratio of omega- 6 to omega-3 fatty acids. The diet eaten by poultry in their natural habitats (wild environments) consists of seeds, plants, insects etc., providing plenty of minerals, micronutrients and plant antioxidants and a much higher proportion of omega-3 fatty acids compared to omega- 6 fatty acids than in those feed mixtures that are now commonly used in commercial poultry production.

The ratio between omega- 6 and omega-3 fatty acids is too high in many of the western societies, increasing the burden of various non-communicable diseases [8]. One of the main reasons for this is the tendency for prostaglandin overproduction in disease situations, when the absolute intake of arachidonic acid (AA) or the ratio of AA to the sum of EPA and DHA in the diet is too high.

Studies on postprandial inflammation as an independent risk factor for diseases such as atherosclerosis and insulin resistance also indicate that each meal triggers an inflammatory response, and that the ratio between omega- 6 and omega-3 fatty acids is an important determinant of the magnitude of this postprandial inflammatory response [9]. In a 
recent study of the specificities of enzymes and prostanoid receptors toward EPA-derived, 3-series versus AA-derived, 2 -series prostanoid substrates and products, the largest difference was seen with $\mathrm{PG}$ endoperoxide $\mathrm{H}$ synthase-1, also called COX-1, compared with COX-2 [10]. Under optimal conditions, it was found that purified COX-1 oxygenates EPA with only $10 \%$ of the efficiency of AA and that EPA significantly inhibits AA oxygenation by COX-1 [10]. 2-fold to 3-fold higher activities or potencies with 2-series versus 3series compounds were observed with COX-2, PGD synthases, microsomal PGE synthase-1, and EP1, EP2, EP3 and FP prostanoid receptors [10]. Surprisingly, it was observed that AA oxygenation by COX-2 is only modestly inhibited by EPA; COX-2 exhibits a marked preference for AA when EPA and AA are tested together [10]. It was also found that thromboxane $\mathrm{A}_{3}\left(\mathrm{TxA}_{3}\right)$ is about equipotent to $\mathrm{TxA}_{2}$ at the TPalpha receptor [10]. These observations predict that increasing the EPA/AA ratios in the phospholipids of human cells would dampen prostanoid signalling with the largest effects being on COX-1 pathways involving PGD, PGE, and PGF, while production of $\mathrm{PGH}_{2}$ from AA by COX-2 would be expected to decrease in proportion to the compensatory decrease in the AA content of phospholipids that would result from increased incorporation of omega-3 fatty acids such as EPA and DHA [10]. Conversion of PGH to PGE is, however, also more rapid in the 2 -series than in the 3 -series of prostaglandins. Enhanced dietary intakes of $18 \mathrm{C}$ polyunsaturated fatty acids linoleic acid (LA) and alpha-linolenic acid (ALA) or of oleic acid will displace AA and reduce its concentration in the membrane lipids of human cells. But a disadvantage of enhancing the total intake of other polyunsaturated fatty acids for reducing the AA concentration of human membrane lipids, rather than reducing the dietary intake of AA, is that this method must be expected to lead to enhanced lipid peroxidation, and some of the ingested LA will also be converted to AA by cells in the human body. Accordingly, the best strategy for avoiding prostanoid overproduction in disease situations where COX-2 is important (e.g. chronic non-infectious inflammatory diseases such as rheumatoid arthritis, other chronic pain conditions and colon cancer) must be to reduce the intake of AA, rather than enhance the intakes of EPA and DHA. In order to achieve this, it is not enough to take fish oil capsules or eat much fat fish. It is necessary either that the patient must reduce the total consumption of AA-rich foods (like poultry, swine and eggs) that now contain too much AA, or the farmers must start to produce poultry meat, swine meat and eggs that have a similar fatty acid composition (with much more EPA and DHA and less AA) as meat and eggs from the same species when living in their natural habitats.

The currently exploited sources of the long-chain omega3 fatty acids EPA, DPA and DHA seem to be limited because of ecological limitations on total fish production in the sea and a tendency for overexploitation of many of the commercially most important fish stocks [11]. Every step towards increasing the concentration of these fatty acids in the regular human diet from sources other than fish may therefore be of importance, if we shall be able to optimize the health of the human population of our planet without simultaneously destroying both its terrestrial and marine ecosystems. We therefore think that all chicken meat available for human consumption (as well as swine meat and eggs) should have a favourable ratio between omega-6 and omega-3 fatty acids, especially when considering the longchain ones such as arachidonic acid (AA), EPA and DHA.

The concentration of selenium in wheat grown in Norway is low (less than 20 microgram Se/ $\mathrm{kg}$ wheat, [12]), mainly as a consequence of poor bioavailability of soil Se for uptake in the plant roots. The commercial chicken feed concentrates are therefore supplemented with $\mathrm{Se}$ to avoid $\mathrm{Se}$ deficiency in the animals, which is given in form of inorganic Se (sodium selenite). There are dual benefits from the Se supplementation: improved health and performance of the animals and improved product quality for human consumption, with increased selenium concentration and decreased drip loss during meat storage [13]. However, much of the sodium selenite added to the feed concentrate is excreted and not incorporated into the meat. Supplementation of the feed with Se-enriched yeast or selenomethionine is much more efficient if the intention is to increase the Se concentration in meat for the benefit of the human consumer $[7,14]$.

As Se is a very scarce trace element on our planet and total resources of commercially exploitable sulphide ores containing Se are limited, the Se concentration in the human diet should be increased in an efficient and sustainable way with as little waste as possible [15]. As a consequence, Se supplementation regimes in feed should be evaluated for sustainability, and organic Se forms that may help to reduce overall waste should be preferred.

A chicken meat containing a favourable ratio between omega-6 and omega-3 fatty acids and especially high Se levels might be desirable both for prophylactic reasons and for making it practically more easy to optimize the composition of the total diet for patients suffering from serious diseases such as cancer, coronary heart disease, rheumatoid arthritis or HIV disease. It has recently been reported that milk from cows fed diets enriched with Se enriched yeast may have a more beneficial impact on bowel cancer compared to other Se supplements [16]. Increasing the Se and omega-3 fatty acid intake through the ordinary diet may be a better strategy, especially when one wishes to reach the entire population, rather than improving Se and omega-3 fatty acid status on a more individual basis by use of pills. At the same time the intake through ordinary foods will be associated with less risk of EPA and DHA peroxidation during storage, compared with fish oil capsules. Also when EPA and DHA come from animal foods rather than as purified dietary supplements, they will be ingested together with antioxidant nutrients that are important for prevention of peroxidation in vivo such as selenium, glutathione (plus GSH precursor amino acids), carnosine and taurine. These antioxidant nutrients protects against tissue damage caused by ischemia and can have antimutagenic, anticarcinogenic, and anti-inflammatory properties, which might be important especially in skeletal muscle pain conditions where antiischemic protective and anti-inflammatory effects both might be helpful.

By adding Se-enriched yeast to the chicken feed concentrate, a chicken meat that contains the same amount of Se as in fish, can be produced [6]. The fatty acid metabolism in Se-deficient animals has been shown to result in reduction of the concentrations of long-chain fatty acids such as DHA and other long chain $\mathrm{C} 20$ and $\mathrm{C} 22$ polyunsaturated fatty ac- 
ids in rats [17]. The reason is not known for certain, but possible roles of $\mathrm{Se}$ in connection with the absorption, storage and desaturation of fatty acids have been discussed. Selenium deficiency may lead to more rapid degradation of long-chain polyunsaturated fatty acids by lipid peroxidation, and in a previous study in broilers given a relatively high Se intake in the feed $(0.50 \mathrm{mg} / \mathrm{kg}$ diet or $0.84 \mathrm{mg} / \mathrm{kg}$ diet $)$, the highest Se intake resulted in increased concentrations of EPA, DPA and DHA in the broiler meat [6].

The myoglobin concentration in muscle is a major determinant of meat color, which is an important aspect of product quality. PPARalpha has been shown to play a role in the regulation of heme biosynthesis in humans, with PPARalpha agonists enhancing the expression of 5aminolevulinate synthetase, which is the rate-limiting enzyme in heme synthesis in the liver [18]. Since EPA and DHA function as PPARalpha agonists [19], it is conceivable that a higher dietary intake of long-chain omega-3 fatty acids might help to increase the rate of heme biosynthesis which might in turn lead to enhancement of the myoglobin concentrations. Heme biosynthesis and degradation are also redoxregulated and since Se is an essential component of several antioxidant enzymes, it is possible that poor Se status might be associated with enhanced heme oxygenase expression which could lead to reduction of the myoglobin concentration. It has not been well studied how much Se in the feed is needed for saturation of myoglobin concentrations in muscle cells. We have therefore found it worthwhile to include myoglobin in our study.

The purpose of the present investigation was to study the concentrations of Se and very long omega-3 fatty acids EPA, DPA and DHA in thigh meat from broilers receiving diets containing high (and up to potentially toxic) level of Se and addition of rapeseed oil and linseed oil as sources of the omega-3 fatty acid alpha-linolenic acid.

\section{MATERIALS AND METHODS}

\section{Methods \\ Animal Care}

The experimental research on animals followed internationally recognized guidelines. All animals were cared for according to laws and regulations controlling experiments with live animals in Norway (The Animal Protection Act of December 20th, 1974, and the Animal Protection Ordinance Concerning Experiments with Animals of January 15th, 1996), according to the rules given by Norwegian Animal Research Authority.

\section{Feeding Experiment}

Sixty newly hatched male broilers (Ross 308, Samvirkekylling, Norway) were randomly assigned for four dietary treatments. The first 10 days the birds in each dietary treatment group were kept together in deep littered pens; 75 $\mathrm{cm} \times 150 \mathrm{~cm}$. At day 10 each individual was weighed and the birds were placed in separate metabolism cages. They were raised in wire-floored battery brooders in an environmentally controlled room with electrical heating. The room temperature was maintained at $32{ }^{\circ} \mathrm{C}$ from days $0-3$, and then gradually reduced by $0.5{ }^{\circ} \mathrm{C}$ per day until day 21 . Chicks were exposed to $23 \mathrm{~h}$ light and $1 \mathrm{~h}$ dark photoperiod during days $0-7$. The next two weeks they were exposed to $2 \times 4 \mathrm{~h}$ dark; the dark periods were between 17-21 $\mathrm{h}$ and 00-04 $\mathrm{h}$. The birds had free access to water. Water troughs were cleaned daily. At day 21 the broilers were sacrificed and muscles were immediately removed and frozen for further analyses. Selenium and individual fatty acid concentrations were determined in thigh muscle, and myoglobin in breast muscle.

\section{Experimental Diets}

The four diets contained wheat (60\%), soybean meal, fish meal, rapeseed oil (Askim Bær- og fruktpresseri, Askim, Norway), linseed oil (Dr. Lindbergs, Oslo, Norway), and nutrient supplements (A/S Norsk Mineralnæring, Hønefoss, Norway) as shown in Table 1. Organic selenium enriched yeast (BioLogics, Ultra Bio-Logics Inc. New O.S.Y. 2000X, containing $2.15 \mathrm{~g} \mathrm{Se} / \mathrm{kg}$ ) was added to the diets, giving the following Se concentrations in four diets: $0.27 \mathrm{mg} / \mathrm{kg}, 0.44$ $\mathrm{mg} / \mathrm{kg}, 0.78 \mathrm{mg} / \mathrm{kg}$ and $1.16 \mathrm{mg} / \mathrm{kg}$ feed, respectively. The dietary treatment groups were named: Se0.27, Se0.44, Se0.78 and Se1.16.

\section{Diet Formulation}

The wheat was ground on a hammer mill, $3 \mathrm{~mm}$ sieve. The feed was manufactured at ForTek, Ås, Norway, with matrix type $2.5 \mathrm{~m} \mathrm{~m} \mathrm{x} 46 \mathrm{~m} \mathrm{~m} .600 \mathrm{~kg}$ /hour, cold pelletation.

The fatty acid concentration of the diets $(\mathrm{g} / 100 \mathrm{~g}$ fat) were: C16:0, 14.3; C18:0, 8.3; C18:1,c9, 37.1; C18:2,n-6, 19.8; C18:3,n-3, 9.0; C20:4,n-6, 0.09; C20:5,n-3, 0.17; $\mathrm{C} 22: 5, \mathrm{n}-3,0.06$; C22:6,n-3, 0.29 .

At day 21 , the birds were weighed and killed by exposure to $\mathrm{CO}_{2}$ gas for $2 \mathrm{~min}$ in a flow-through system and breast muscle and thigh was immediately removed and frozen for further analyses.

\section{Laboratory Analyses}

\section{Fatty acid Analyses}

Fatty acid composition of thigh muscle and feed were determined by gas chromatography. Lipid extraction and direct methylation were performed according to [20] on $1 \mathrm{~g}$ of thigh muscle tissue or feed. Subsequently, the fatty acid methyl esters were analyzed with a $6890 \mathrm{~N}$ GC with a split/splitless injector, a 7683B automatic liquid sampler, and flame ionization detection (Agilent Technologies, Palo Alto, CA ). Separation was performed with a CP-SELECT CB FOR FAME $(200 \mathrm{~m} \times 0.25 \mathrm{~mm}$ i.d. $\times 0.25 \mu \mathrm{m}$ film thickness) fused silica capillary column (Varian Inc.). Temperature program, initial: $70^{\circ} \mathrm{C}$ with 4 min hold, ramp $20^{\circ} \mathrm{C} / \mathrm{min}$ to $160{ }^{\circ} \mathrm{C}, 3{ }^{\circ} \mathrm{C} / \mathrm{min}$ to $230^{\circ} \mathrm{C}$ with $15 \mathrm{~min}$ hold. The carrier gas was $\mathrm{H}_{2}$, and a pressure of $309.4 \mathrm{kPa}$ was used. Fatty acid analysis was performed by autoinjection of $1 \mu \mathrm{L}$ of each sample at a split ratio of $30: 1, \mathrm{a} \mathrm{H}_{2}$ flow of $68.4 \mathrm{ml} / \mathrm{min}$ and a temperature of $280{ }^{\circ} \mathrm{C}$. The flame ionization detector temperature was $290{ }^{\circ} \mathrm{C}$ with $\mathrm{H}_{2}$, air and $\mathrm{N}_{2}$ make-up gas flow rates of 40,450 and $45 \mathrm{ml} / \mathrm{min}$ respectively. The sampling frequency was $10 \mathrm{~Hz}$. The run time for a single sample was 91.83 min. Fatty acid peaks determined by gas chromatography were then used to calculate the amounts of fatty acids (g/100 g fat) by theoretical response factors [21]. Standard 
Table 1. Diet Composition (Ingredients in Percent)

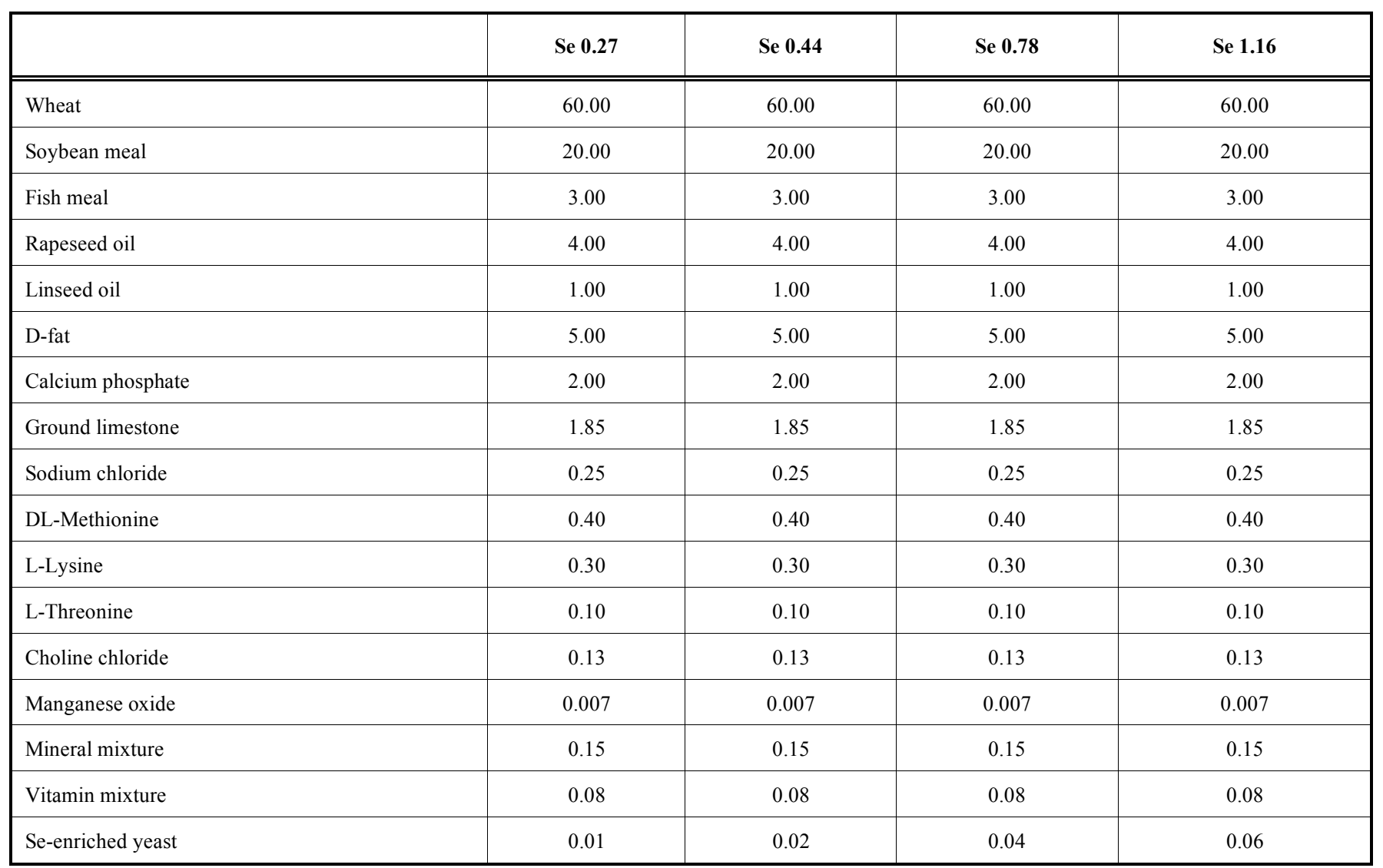

The vitamin and mineral mixture provided per kg diet: retinyl acetate, $2.7 \mathrm{mg}$; cholecalciferol, $0.07 \mathrm{mg}$; DL-alpha tocopheryl acetate, $38 \mathrm{mg}$; menadione, $2.25 \mathrm{mg}$; pyridoxine, 3.4 $\mathrm{mg}$; riboflavin, $9 \mathrm{mg}$; Ca-pantothenate, $12.5 \mathrm{mg}$; biotin, $0.19 \mathrm{mg}$; thiamine, $1.9 \mathrm{mg}$; niacin, $37.5 \mathrm{mg}$; cobalamine, $0.02 \mathrm{mg}$; folic acid, $1.5 \mathrm{mg}$; choline chloride, $500 \mathrm{mg}$; manganese, $75 \mathrm{mg}$; zinc, $75 \mathrm{mg}$; iron, $95 \mathrm{mg}$; copper, $10 \mathrm{mg}$; iodine, $0.6 \mathrm{mg}$.

fatty acids of known composition were run to identify the fatty acids in the samples. Muscle control samples were extracted, methylated and analysed by every $10^{\text {th }}$ sample.

\section{Determination of Selenium in Thigh Muscle}

Selenium concentrations in the diets and in thigh muscle of each of the 57 broilers were analyzed by atomic absorption spectrometry with a hydride generator system [22], using Varian SpectrAA-30 with a VGA - 76 vapour generation accessory. Before analysis, each sample was prepared by oxidative digestion in a mixed solution with concentrated nitric and perchloric acids, using an automated system with Tecator 1012 Controller and 1016 Digester heating unit. The method is accredited (NS-EN ISO/IEC 17025). A quality control system used regular analyses of a pork liver (GWB) with $0.94+0.05 \mathrm{ug} \mathrm{Se} / \mathrm{g}$ and a bovine muscle (BCR 184) with $0.183+0.012 \mathrm{ug} \mathrm{Se} / \mathrm{g}$ as reference materials. The detection limit was $0.01 \mathrm{ug} / \mathrm{g}$, and the quantification limit 0.03 $\mathrm{ug} / \mathrm{g}$.

\section{Determination of fat Percentage in Muscle}

The percentage of fat was determined in thigh muscle by ASE, Dionex, USA, application note 329, Dionex.

\section{Determination of Myoglobin (Oxidized Heme Proteins) in Breast Muscle}

An estimate of the concentration of myoglobin (oxidized heme proteins) was performed in frozen breast muscle by measuring the difference in absorption spectra of the oxidized heme proteins between the peak at about $408 \mathrm{~nm}$ and 'baseline' at $440 \mathrm{~nm}$ [23].

Frozen samples of breast muscle (2 gram) were homogenized in $12 \mathrm{ml} 50 \mathrm{mM}$ potassium phosphate buffer, $\mathrm{pH} 6.9$ and centrifuged at $20.000 \mathrm{rpm}$ for $1 \mathrm{~h}$ before absorption of the supernatant was read in a Shimadzu spectrophotometer at wavelength between lambda $350 \mathrm{~nm}$ and $500 \mathrm{~nm}$.

\section{Statistical Analyses}

Statistical calculations of the effects of the dietary treatments on final body weight, fatty acid composition and myoglobin were performed by SPSS 15.0 (spss.com) for Windows, comparing means by one-way ANOVA and Bonferoni test for assumption of equal variances.

\section{RESULTS AND DISCUSSION}

Final body weight of the broilers (21 days old when slaughtered) was not affected by the dietary treatments; final body weight did not differ among the experimental groups, and the weights were as expected for 21 days old broilers.

Three birds died during the experiment, one from group $\mathrm{Se} 0.27$ and two from group Se1.16. This level of mortality rate is not uncommon in experiments involving birds living in metabolism cages, and the birds did not undergo a post mortem autopsy. The average fat concentration in thigh 
muscles was $3.2 \%$, and there was no difference among the dietary treatment groups.

The selenium concentration in thigh muscle was significantly different $(p<0.05)$ among all the dietary treatment groups (Table 2). The Se concentration in raw thigh muscle was about $0.2,0.3,0.4$ or $0.6 \mathrm{mg} / \mathrm{kg}$ muscle following a supplementation of $0.1 \%, 0.2 \%, 0.4 \%$ or $0.6 \%$ Se enriched yeast to the diet, respectively, showing that the incorporation of Se in muscle declined with increasing Se concentrations in the diet. This is in accordance to earlier studies [6,24]. The Se concentration in the broiler meat in group Se1.16 was high. A portion of $130 \mathrm{~g}$ of this meat would give about $0.08 \mathrm{mg}$ Se. This is about two times higher than the presently recommended daily intake [25], but less than half of the supplementation level of $0.2 \mathrm{mg} \mathrm{Se} /$ day that has been shown to reduce risk of lung, colorectal and prostate cancer [26]. An equally large portion of meat from the dietary treatment group Se 0.27 would give about $0.025 \mathrm{mg} \mathrm{Se}$, about half of the recommended intake. Upper levels of Se intake in humans have been discussed, but a "no observed adverse effect level" (NOAEL) has been reported at $0.85 \mathrm{mg} /$ day [25].

If the meat was intended for special groups of patients, e.g. as part of hospital or other institutional diets for patients suffering from ischemic pain, the higher level of Se supplementation could be recommended, since it has been found in animal experiments that $\mathrm{Se}$ at high dosage levels has a significant antiischemic protective effect [27-29] and also enhances to a very significant extent the time before respiratory and cardiac arrest in mice subject to global anoxia by inhalation of pure nitrogen [30].

The concentrations of Se in thigh muscle in treatment group $\mathrm{Se} 0.44$ and $\mathrm{Se} 0.78$ were comparable to the Se concentrations found in a previous study [6]: $0.02 \%$ Se rich yeast (as in diet $\mathrm{Se} 0.44$ ) gave a thigh muscle concentration of 0.28 $\mathrm{mg} / \mathrm{kg}$ muscle, and $0.04 \%$ Se rich yeast (as in diet $\mathrm{Se} 0.78$ ) gave a muscle concentration of $0.39 \mathrm{mg} / \mathrm{kg}$ muscle.

There were no observable differences in estimated myoglobin concentrations (oxidized heme proteins) in breast muscle among the dietary treatment groups. The method used was a simple spectrophotometric reading for assessment of oxidized heme proteins, and a more advanced method, giving better precision, would have been a preferred choice. But it is also possible that the minimal Se requirement needed for saturation of myoglobin concentrations in skeletal muscle in otherwise healthy animals is less than was used in our experiments.

In the present study the thigh meat was enriched in very long chain fatty acids when compared to regular chicken thigh meat; the present thigh meat contained about $0.13 \mathrm{~g}$ EPA, DPA and DHA /100 g meat, and this is about the double of what is reported in the Danish food composition table for chicken thigh [2]. The increased muscle content of very long chain omega-3 fatty acids following supplementation of alpha-linolenic acid to chicken are in accordance with other studies $[5,6]$. Still, the present amount of very long chain omega-3 fatty acids may not be as high as the maximum that might be practically possible to obtain without detrimental effects on the health of the animals or on product quality (organoleptic properties and storage stability), and further attempts could give higher levels. Thus, broiler meat may give a significant contribution to the dietary intake of EPA, DPA and DHA and be close to rival lean fish such as cod in its content of the very long chain omega-3 fatty acids. Fatty fish such as herring, mackerel and salmon are still, however, much better sources of these fatty acids.

The experimental diets contained $40 \mathrm{~g}$ rapeseed oil and $10 \mathrm{~g}$ linseed oil per $\mathrm{kg}$ diet. This diet gave a broiler meat having a favorably low ratio between omega- 6 and omega-3 fatty acids; being about $2: 1$ and the ratio between AA and EPA about $3: 1$. This ratio is important since omega-6 and omega-3 fatty acids compete with each other for binding to enzymes and incorporation into membrane lipids [31], and omega-3 fatty acids also suppress the expression of inflammatory genes, whereas omega-6 fatty acids have an opposite effect. Inflammation takes place within the vascular walls and plays a role in modulating the effect of insulin and control of inflammatory gene expression and lipid metabolism [32]. In addition, the ratio between omega-6 and omega-3 also influences several processes at the cellular level including cell growth, multiplication, apoptosis and cell survival [32]. Thus the broiler meat in the present study is a better alternative than regular broiler meat. It is possible that an optimal feed mixture should contain even more linseed oil, so as to bring the ratio between omega-6 and omega-3 fatty acids even lower, but this would perhaps require the broiler feed to be stored in dark and air-tight containers under inert gas (nitrogen) to avoid the feed becoming rancid.

In the present study, no significant increase in the concentrations of the long chain fatty acids EPA, DPA and DHA in thigh muscle was observed following increased supplementation with Se-enriched yeast, and the concentration of the main fatty acids in broiler thigh meat are nearly identical with the four Se-treatments, (Table 2). In a previous study, however, $0.84 \mathrm{mg} \mathrm{Se} / \mathrm{kg}$ diet resulted in increased concentration of EPA, DPA and DHA in thigh muscle compared to $0.50 \mathrm{mg} \mathrm{Se} / \mathrm{kg}$ diet [6]. As can be seen in Table 2, there is a tendency towards an increased concentration of EPA, DPA and DHA in thigh muscle in the dietary treatment giving $0.78 \mathrm{mg} \mathrm{Se} / \mathrm{kg}$ diet compared to the dietary treatment having $0.44 \mathrm{mg} \mathrm{Se} / \mathrm{kg}$ diet, but the differences do not reach significance. A possible reason could be saturation of the antioxidative protective effects of Se when the Se intake becomes very high (which in part might be explained by saturation of Se-dependent antioxidative enzymes), while even higher intakes will cause prooxidant effects of Se to become relatively more important, compared with the antioxidant effects [33]. The concentration of the other main fatty acids is not affected by Se intake, and this is in accordance to a previous study [6].

\section{CONCLUSION}

Thigh meat from broilers raised on a feed supplemented with $40 \mathrm{~g}$ rapeseed oil, $10 \mathrm{~g}$ linseed oil per $\mathrm{kg}$ diet and 0.27 , $0.44,0.78$ or $1.16 \mathrm{mg}$ Se per $\mathrm{kg}$ diet can be described as a functional food. The diet gave no indication of adverse (toxic) effects on the animals even at the highest level of Se intake. We believe this broiler meat is a good contribution to a better strategy for increasing the food content of Se and very long chain omega-3 fatty acids and for correcting the dietary balance between omega- 6 and omega-3 fatty acids rather than relying on dietary supplements in form of Se pills 
Table 2. Final Body Weight (FBW), g, Selenium (Se) Concentration in Broiler Thigh Muscle, mg/kg Wet Weight, fatty Acid Composition of Broiler Thigh Muscle, g/100 g Fatty Acid Methyl Ester, and Myoglobin Concentration in Breast Muscle Estimated as cm Peak Height at Max Absorption (at Lambda 409- $410.5 \mathrm{~nm}$ ) and 'Baseline' at $440 \mathrm{~nm}$. Values are Means and (SD).

\begin{tabular}{|c|c|c|c|c|c|c|c|c|}
\hline \multirow[b]{2}{*}{ FBW } & \multicolumn{2}{|c|}{ Se 0.27} & \multicolumn{2}{|c|}{ Se 0.44} & \multicolumn{2}{|c|}{ Se 0.78} & \multicolumn{2}{|c|}{ Se 1.16} \\
\hline & 899 & (43) & 905 & (81) & 928 & (69) & 923 & (64) \\
\hline $\mathrm{C} 16: 0$ & $16.1^{\mathrm{a}}$ & $(0.6)$ & $15.3^{\mathrm{b}}$ & $(0.7)$ & $15.4^{\mathrm{a}, \mathrm{b}}$ & $(0.9)$ & $15.1^{\mathrm{b}}$ & $(0.6)$ \\
\hline $\mathrm{C} 16: 1, \mathrm{c} 9$ & 2.4 & $(0.5)$ & 2.2 & $(0.5)$ & 2.3 & $(0.5)$ & 2.0 & $(0.5)$ \\
\hline $\mathrm{C} 18: 1, \mathrm{c} 9$ & 33.2 & (3.7) & 33.5 & $(2.6)$ & 32.6 & $(4.1)$ & 33.2 & $(3.6)$ \\
\hline C18:2,n-6, LA & 15.7 & $(0.7)$ & 15.9 & $(1.0)$ & 15.6 & $(1.0)$ & 16.3 & $(0.6)$ \\
\hline C18:3,n-3, ALA & 4.9 & $(0.8)$ & 4.7 & $(0.6)$ & 4.6 & $(0.7)$ & 4.8 & $(0.9)$ \\
\hline C22:5,n-3, DPA & 1.5 & $(0.5)$ & 1.5 & $(0.4)$ & 1.7 & $(0.5)$ & 1.4 & $(0.5)$ \\
\hline C22:6,n-3, DHA & 1.6 & $(0.6)$ & 1.5 & $(0.4)$ & 1.7 & $(0.6)$ & 1.6 & $(0.6)$ \\
\hline $\mathrm{AA} / \mathrm{EPA}$ & $2.9^{\mathrm{b}}$ & $(0.6)$ & $3.0^{\mathrm{a}, \mathrm{b}}$ & $(0.5)$ & $2.8^{\mathrm{b}}$ & $(0.5)$ & $3.6^{\mathrm{a}}$ & $(0.7)$ \\
\hline$n-6 / n-3$ & $2.0^{\mathrm{b}}$ & $(0.1)$ & $2.1^{\mathrm{a}, \mathrm{b}}$ & $(0.1)$ & $2.0^{\mathrm{b}}$ & $(0.1)$ & $2.1^{\mathrm{a}}$ & $(0.2)$ \\
\hline Myoglobin & 1.5 & $(0.3)$ & 1.4 & $(0.4)$ & 1.5 & $(0.4)$ & 1.5 & $(0.4)$ \\
\hline
\end{tabular}

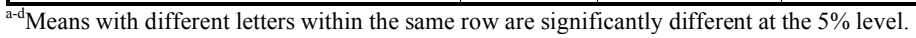

and fish capsules, or on fish resources that are already overexploited and can not cover EPA and DHA requirements (for ensuring optimal health) for more than a fraction of the world's total population.

\section{ACKNOWLEDGEMENT}

This work was supported by the Norwegian Research Council. The assistance of colleagues at IHA, IKBM and SHF at The Norwegian University of Life Sciences, Aas, and at the National Veterinary Institute, Oslo, all Norway, are gratefully acknowledged. With special thanks to J Volden, E Slinde, A Bernhoft, M B Skarra, O Sandaas and I J Jorgensen.

AH contributed in planning, experimental work, analysis and publication of results, OAC contributed in planning of the experiment, discussing the results and writing the article and TS contributed in planning of the experiment, and in providing funding for the experiment. All authors read and approved the findings of the study. The authors have no conflicts of interest in this research.

\section{REFERENCES}

[1] Norwegian dietary information. Utviklingen i norsk kosthold. Sosial og Helsedirektoratet, Oslo, Norway. 2004.

[2] DTU, Danish Food Composition Databank. Available at: http://www.foodcomp.dk/v7/fvdb_search.asp (Accessed June 29, 2009).
Matportalen, Matvaretabellen.

Available at: http://matportalen.no/matvaretabellen. (Accessed April 3, 2009).

[4] USDA Nutrient database, USDA Food Composition Data. Available at: http://www.nal.usda.gov/fnic/foodcomp/Data/. (Accessed April 3. 2009).

[5] Ponte PI, Prates JA, Crespo JP, et al. Improving the lipid nutritive value of poultry meat through the incorporation of a dehydrated leguminous-based forage in the diet for broiler chicks. Poult Sci 2008; 87: 1587-94.

[6] Haug A, Eich-Greatorex S, Bernhoft A, et al. Effect of dietary selenium and omega-3 fatty acids on muscle composition and quality in broilers. Lipids Health Dis 2007a; 6: 29.

[7] Fisinin VI, Papazyan TT, Surai PF. Selenium in poultry nutrition. In: Surai PT, Taylor-Pickard JA, Eds. Current advances in selenium research and applications. Academic Publishers: Wageningen 2008.

[8] Simopoulos AP. The importance of the ratio of omega-6/omega-3 essential fatty acids. Biomed Pharmacother 2002; 56: 365-79.

[9] Margioris AN. Fatty acids and postprandial inflammation. Curr Opin Clin Nutr Metab Care 2009; 12: 129-37.

[10] Wada M, DeLong CJ, Hong YH, et al. Enzymes and receptors of prostaglandin pathways with arachidonic acid-derived versus eicosapentaenoic acid-derived substrates and products. J Biol Chem 2007; 282: 22254-66.

[11] Clover C. The end of the line. How overfishing Is changing the world and what we eat. Ebury Press: London 2005.

[12] Ruud, L. Forsøksrapport 1997. Samarbeidsprosjekt IJVF. Norsk Hydro ASA. Rapport. Institutt for jord- og vannfag, Norges landbrukshøgskole. (In Norwegian) 1997; 6: pp. 56, 89.

[13] Surai PF. Selenium Nutrition and Health. Nottingham University Press: Nottingham 2006

[14] Payne RL, Southern LL. Comparison of inorganic and organic selenium sources for broilers. Poult Sci 2005; 84: 898-902.

[15] Haug A, Graham RD, Christophersen OA, Lyons GH. How to use the world's scarce selenium resources efficiently to increase the se- 
lenium concentration in food. Microbial Ecol Health Dis 2007b; 19: $209-28$

[16] Hu Y, McIntosh GH, Le Leu RK, Woodman R, Young GP. Suppression of colorectal oncogenesis by selenium-enriched milk proteins: apoptosis and K-ras mutations. Cancer Res 2008; 68: 493644.

[17] Schäfer K, Kyriakopoulos A, Gessner H, Grune T, Behne D. Effects of selenium deficiency on fatty acid metabolism in rats fed fish oil-enriched diets. J Trace Elem Med Biol 2004; 18: 89-97.

[18] Degenhardt T, Väisänen S, Rakhshandehroo M, Kersten S, Carlberg C. Peroxisome proliferator-activated receptor alpha controls hepatic heme biosynthesis through ALAS1. J Mol Biol 2009; 388(2): 225-38.

[19] Flachs P, Rossmeisl M, Bryhn M, Kopecky J. Cellular and molecular effects of n-3 polyunsaturated fatty acids on adipose tissue biology and metabolism. Clin Sci (Lond) 2009; 116: 1-6.

[20] O'Fallon JV, Busboom JR, Nelson ML, Gaskins CT. A direct method for fatty acid methyl ester synthesis: application to wet meat tissues, oils, and feedstuffs. J Anim Sci 2007; 85: 1511-21.

[21] Ackman RG, Sipos JC. Flame ionization detector response for the carbonyl carbon atom in the carboxyl group of fatty acids and esters. J Chromatogr 1964; 16: 298-305.

[22] Norheim G, Haugen A. Precise determination of selenium in tissues using automated wet digestion and an automated hydride generator-atomic absorption spectroscopy system. Acta Pharmacol Toxicol (Copenh) 1986; 59: 610-2.

[23] Wittenberg JB, Wittenberg BA. Preparation of myoglobins. Methods Enzymol 1981; 76: 29-42.
[24] Haug A, Eich-Greatorex S, Bernhoft A, Hetland H, Sogn T. Selenium bioavailability in chicken fed selenium-fertilized wheat. Acta Agric Scand: Section A 2008; 58: 65-70

[25] Nordic Nutrition Recommendations 2004. Nordic Council, Copenhagen: Denmark 2004

[26] Clark LC, Combs GF Jr, Turnbull BW, et al. Effects of selenium supplementation for cancer prevention in patients with carcinoma of the skin. A randomized controlled trial. Nutritional Prevention of Cancer Study Group. JAMA 1996; 276: 1957-63.

[27] Poltronieri R, Cevese A, Sbarbati A. Protective effect of selenium in cardiac ischemia and reperfusion. Cardioscience 1992; 3: 15560 .

[28] Huang Y, Liu Y, Zhang Z. [Mechanism of selenium defending against free radical damages during myocardial ische$\mathrm{mia} /$ reperfusion in human] [Article in Chinese]. Zhonghua Yi Xue Za Zhi 1999; 79: 731-4.

[29] Turan B, Saini HK, Zhang M, Prajapati D, Elimban V, Dhalla NS. Selenium improves cardiac function by attenuating the activation of NF-kappaB due to ischemia-reperfusion injury. Antioxid Redox Signal 2005; 7: 1388-97.

[30] Aviado DM, Drimal J, Watanabe T, Lish PM. Cardiac effects of sodium selenite. Cardiology 1975; 60: 113-20.

[31] Insel P, Turner RE, Ross D, Eds. Nutrition. $2^{\text {nd }}$ ed. American Dietetic Association. Jones and Barlett Publishers: Ma, USA 2004.

[32] Schmitz G, Ecker J. The opposing effects of n-3 and n-6 fatty acids. Prog Lipid Res 2008; 47: 147-55.

[33] Chen T, Wong YS. Selenocystine induces reactive oxygen speciesmediated apoptosis in human cancer cells. Biomed Pharmacother 2009; 63: 105-13.

(C) Haug et al.; Licensee Bentham Open.

This is an open access article licensed under the terms of the Creative Commons Attribution Non-Commercial License (http://creativecommons.org/licenses/by-nc/3.0/) which permits unrestricted, non-commercial use, distribution and reproduction in any medium, provided the work is properly cited. 